Supporting Information

\title{
Copper-Doped ZnS with Internal Phase Junctions for Highly Selective CO Production from $\mathrm{CO}_{2}$ Photoreduction
}

Xiandi Zhang, ${ }^{1,2,+}$ Daekyu Kim, ${ }^{2,+}$ and Lawrence Yoon Suk Lee ${ }^{1,2,3, *}$

1 The Hong Kong Polytechnic Shenzhen Research Institute, Nanshan, Shenzhen, China

${ }^{2}$ Department of Applied Biology and Chemical Technology and the State Key Laboratory of Chemical Biology and Drug Discovery, The Hong Kong Polytechnic University, Hung Hom, Kowloon, Hong Kong SAR, China

${ }^{3}$ Research Institute for Smart Energy, The Hong Kong Polytechnic University, Hung Hom, Kowloon, Hong Kong SAR, China

$\dagger$ These authors equally contributed to this work.

*E-mail: lawrence.ys.lee@polyu.edu.hk (L. Y. S. Lee)

Keywords: $\mathrm{CO}_{2}$ reduction reaction; photocatalysis; multiple phase junction; $\mathrm{Cu}$ doping; zinc sulfide 


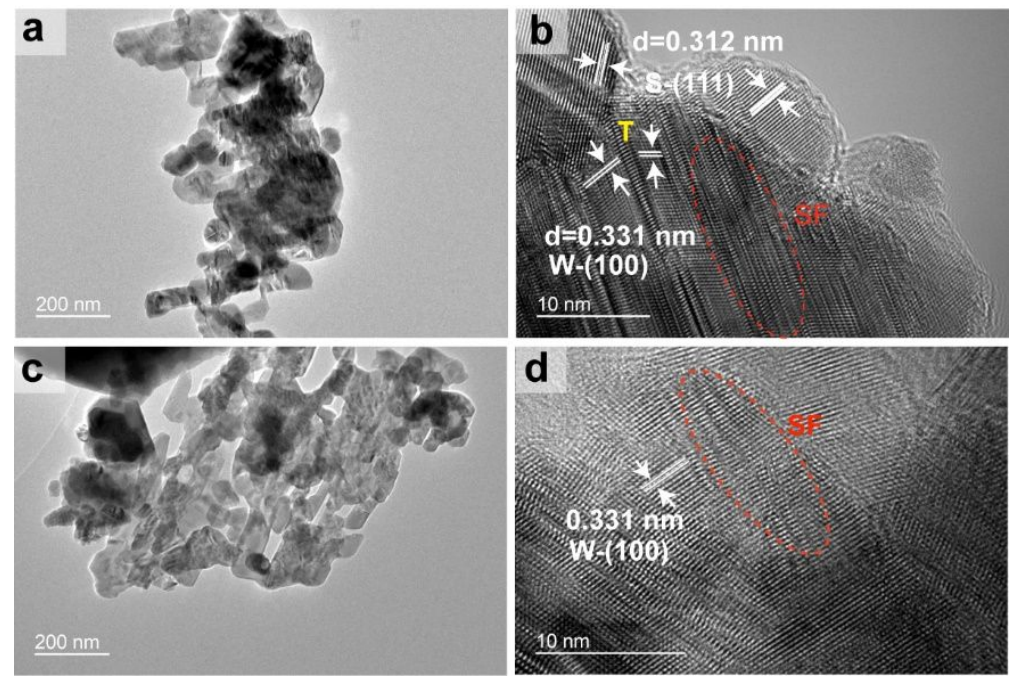

Figure S1. TEM images of (a) $\mathrm{Cu}_{0.05}-\mathrm{ZnS}$ and (c) $\mathrm{ZnS}$. HRTEM images of (b) $\mathrm{Cu}_{0.05}-\mathrm{ZnS}$ and (d) $\mathrm{ZnS}$.

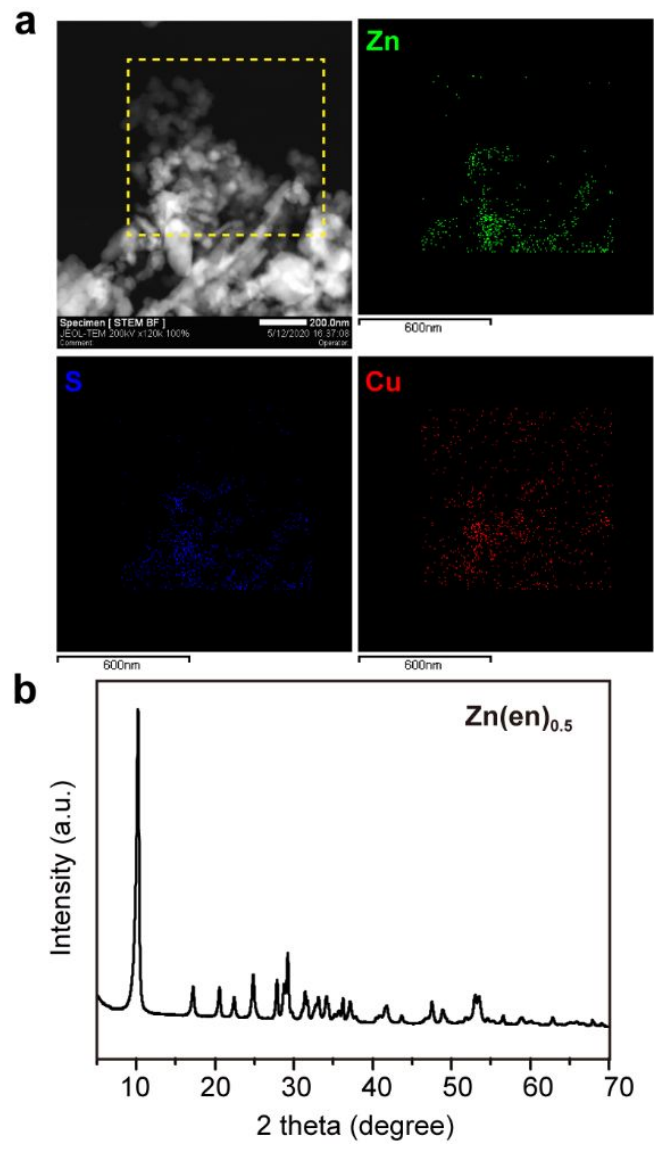

Figure S2. (a) STEM elemental mappings of $\mathrm{Cu}_{0.1}-\mathrm{ZnS}$ and (b) XRD pattern of $\mathrm{Zn}(\mathrm{en})_{0.5}$. 


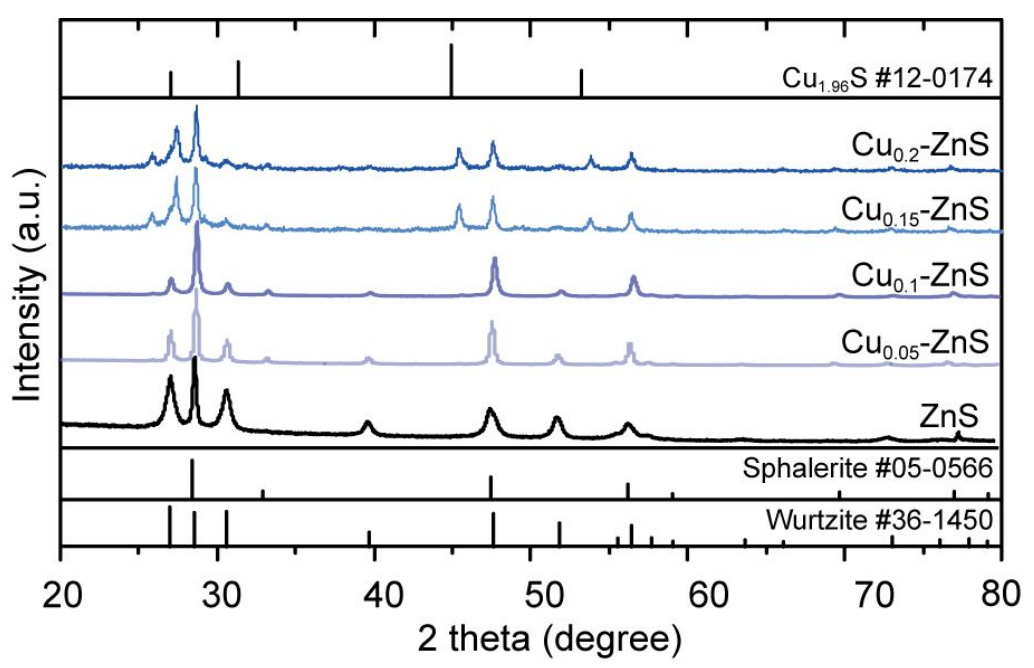

Figure S3. XRD pattern of $\mathrm{Cu}_{0.15}-\mathrm{ZnS}$ and $\mathrm{Cu}_{0.2}-\mathrm{ZnS}$.

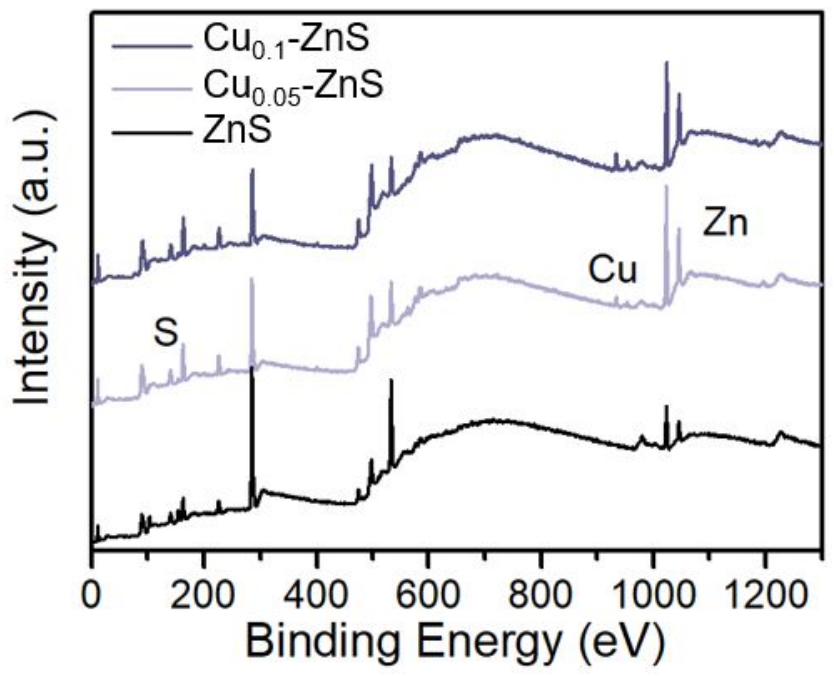

Figure S4. XPS survey spectra of $\mathrm{ZnS}, \mathrm{Cu}_{0.05}-\mathrm{ZnS}$, and $\mathrm{Cu}_{0.1}-\mathrm{ZnS}$. 


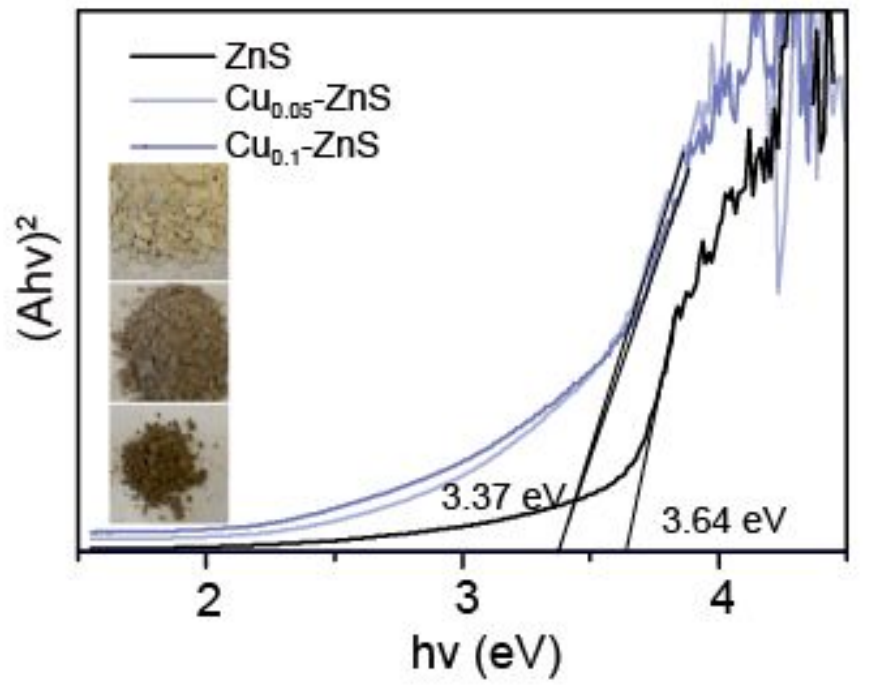

Figure S5. Tauc plots of $\mathrm{ZnS}, \mathrm{Cu}_{0.05}-\mathrm{ZnS}$, and $\mathrm{Cu}_{0.1}-\mathrm{ZnS}$. Insets are digital photos of $\mathrm{ZnS}$ (top), $\mathrm{Cu}_{0.05}-\mathrm{ZnS}$ (middle), and $\mathrm{Cu}_{0.1}-\mathrm{ZnS}$ (bottom).
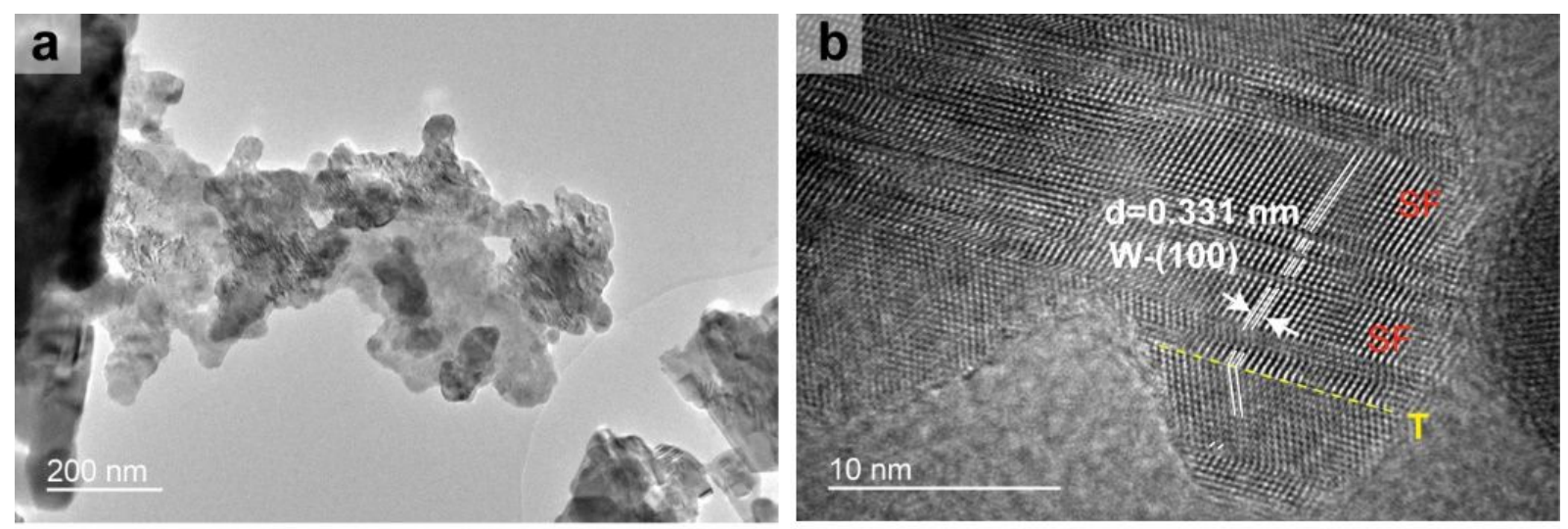

Figure S6. TEM images of $\mathrm{Cu}_{0.1}-\mathrm{ZnS}$ after photocatalysis for 10 hours. 

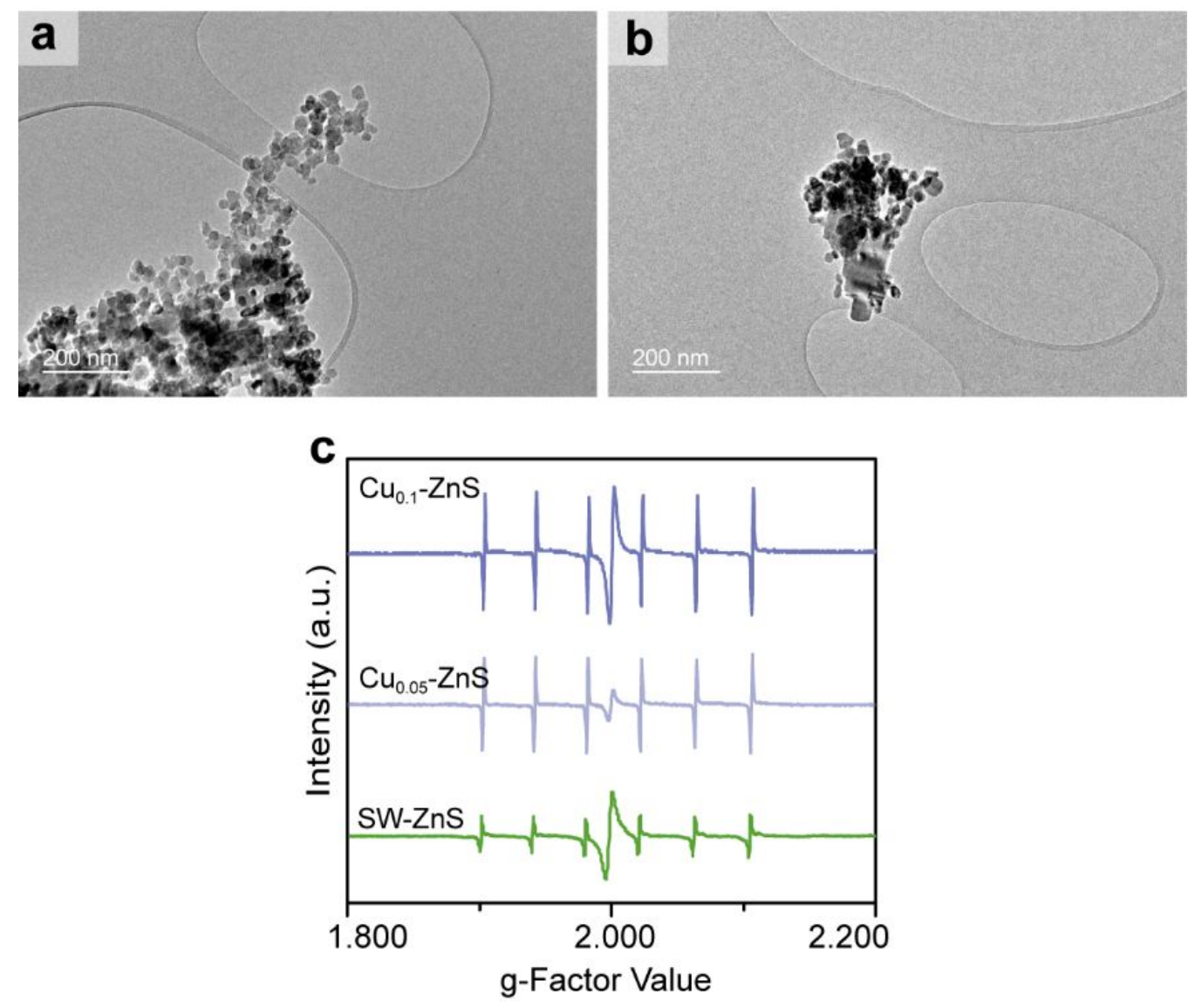

Figure S7. (a, b) TEM images of SW-ZnS. (c) ESR spectra of SW-ZnS, $\mathrm{Cu}_{0.05}-\mathrm{ZnS}$, and $\mathrm{Cu}_{0.1^{-}}$ $\mathrm{ZnS}$.

a
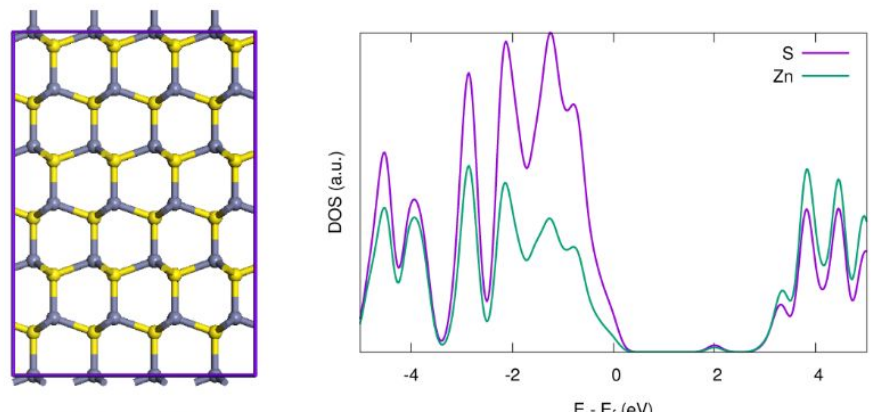

$\bigcirc \mathrm{Zn} \odot \mathrm{S}$
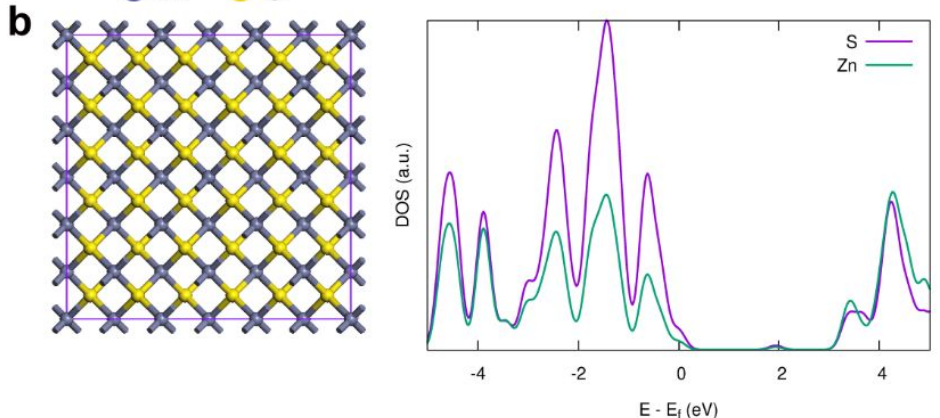

Figure S8. The most stable atomic configurations and PDOS of (a) wurtzite and (b) sphalerite $\mathrm{ZnS}$. 
Table S1. Elemental compositions of $\mathrm{ZnS}, \mathrm{Cu}_{0.05}-\mathrm{ZnS}$, and $\mathrm{Cu}_{0.1}-\mathrm{ZnS}$ based on EDS results.

\begin{tabular}{cccc}
\hline & $\mathbf{Z n ~ ( \% )}$ & $\mathbf{C u}(\%)$ & S (\%) \\
\hline $\mathbf{Z n S}$ & 52.11 & - & 47.89 \\
$\mathbf{C u}_{\mathbf{0 . 0 5}}-\mathrm{ZnS}$ & 47.46 & 7.28 & 45.26 \\
$\mathbf{C u}$ & 46.28 & 11.60 & 42.12 \\
\hline
\end{tabular}

